\title{
Short-term effect of pudendal nerve electrical stimulation on detrusor hyperreflexia in spinal cord injury patients: importance of current strength
}

\author{
JG Prévinaire ${ }^{1}, \mathrm{JM}_{\text {Soler }}{ }^{2}, \mathrm{M}$ Perrigot $^{3}, \mathrm{G}_{\text {Boileau }}{ }^{1}, \mathrm{H}$ Delahaye ${ }^{1}$, P Schumacker ${ }^{1}$, J Vanvelcenaher ${ }^{1}$ and $^{\text {J }}$ \\ JL Vanhée ${ }^{1}$ \\ ${ }^{1}$ Centre de Rééducation Fonctionnelle L'Espoir, 25 Pavé du Moulin BP 1, 59260 Lille-Hellemmes; ${ }^{2}$ Centre Médical du \\ Cap Peyrefite, Cerbère; and ${ }^{3}$ Hôpital Pitié-Salpétrière, Paris
}

\begin{abstract}
Twenty patients with chronic suprasacral spinal cord injury presenting with detrusor hyperreflexia were examined. In a preliminary study in ten patients we investigated the reproducibility of bladder capacity through the repetition of three cystometries. The effect of electrical stimulation (ES) on detrusor hyperreflexia was then investigated in ten patients during three consecutive cystometries, the first one without ES (baseline) and the other two with continuous ES of the dorsal penile or clitoris nerve via surface electrodes. Parameters of stimulation were $5 \mathrm{~Hz}$ frequency, $0.50 \mathrm{msec}$ pulse duration, and stimulation strength of 1 and 2 times the bulbocavernosus reflex threshold.

No significant differences in bladder capacity were found between the three consecutive cystometries without ES (respectively $97.0 \mathrm{ml}, 101.5 \mathrm{ml}$ and $105.6 \mathrm{ml}$ ). A current at the bulbocavernosus threshold (mean $24.4 \mathrm{~mA}$ ) failed to induce a significant increase in bladder capacity compared to baseline $(173.0 \mathrm{ml} v \mathrm{~s} 155.5 \mathrm{ml}, P=0.17)$ whereas a current of twice the bulbocavernosus threshold (mean $48.9 \mathrm{~mA})$ was highly significant $(318.5 \mathrm{ml} v \mathrm{~s} 155.5 \mathrm{ml}, P<$ 0.007). ES of twice the threshold resulted in perineal contraction in all of the patients, the threshold ES never did.

Our results emphasise the decisive roles of perineal contraction and of current strength for achieving short-term bladder inhibition in spinal cord injury patients. The carry-over effect may also be dependent on the current strength. If so, maximal pudendal ES could represent an alternative procedure in the treatment of detrusor hyperreflexia in these patients.
\end{abstract}

Keywords: spinal cord injury; electrical stimulation; detrusor hyperreflexia; bladder inhibition; bulbocavernosus reflex; perineal contraction

\section{Introduction}

Bladder hyperreflexia with resultant incontinence is a major problem in spinal cord injury (SCI) patients. Pharmacological treatments, such as anticholinergic agents, are not always successful in achieving satisfactory bladder inhibition. In the seventies, some authors suggested the use of perineal electrical stimulation (ES) as an alternative treatment. ${ }^{1-4}$ Later three studies demonstrated that ES of pudendal nerve afferents could induce short-term bladder inhibition in these patients. $^{5-7}$ However, uncertainty remains with regard to the current strength: Vereecken et al. and Vodusek et al. reported maximal bladder inhibition with strong $\mathrm{ES},{ }^{5,6}$ whereas Wheeler et al. observed optimal bladder effect with lower currents, close to the threshold for pelvic twitching activity. ${ }^{7}$

Correspondence: JG Prévinaire, Centre Hélène Borel, Chàteau du Liez-BP1, F-59283 Raimbeaucourt, France
The aim of this study was to investigate the efficacy of pudendal nerve ES on detrusor hyperreflexia in SCI patients and to consider the role of current strength. This could indicate a clinical use of maximal ES in the treatment of detrusor hyperreflexia in these patients. The reproducibility of cystometric bladder capacity was assessed in a preliminary study without ES.

\section{Methods}

\section{Subjects}

Twenty patients with chronic suprasacral SCI were examined (Table 1). The selection of the patients was based on the presence of detrusor hyperreflexia confirmed by previous urodynamic studies. The first 10 patients were included in the study of reproducibility, the other 10 supported the study of the effects of ES. The anticholinergic drugs were stopped at least 
Table 1 Characteristics of patients

\begin{tabular}{lcc}
\hline & Reproducibility & $E S$ \\
\hline Sex ratio & $9 \mathrm{M} / 1 \mathrm{~F}$ & $9 \mathrm{M} / 1 \mathrm{~F}$ \\
Age at injury & & 30.7 years \pm 9.7 \\
$\quad$ mean $\pm \mathrm{SD}$ & 34.1 years \pm 8.5 & $18-45$ years \\
range & $22-47$ years & 28.9 months \pm 29.5 \\
Time since injury & 58.2 months \pm 43.4 & $3-97$ months \\
mean $\pm \mathrm{SD}$ & $8-145$ months & $\mathrm{C} 4-\mathrm{T} 10$ \\
range & $\mathrm{C} 4-\mathrm{T} 12$ & 2 \\
Injury level & 6 & 4 \\
tetraplegia, complete (Frankel A) & 0 & 3 \\
tetraplegia, incomplete (Frankel B or C) & 1 & 1 \\
paraplegia, complete (Frankel A) & 3 & 7 \\
paraplegia, incomplete (Frankel B or C) & 6 & 3 \\
Voiding modes & 4 & \\
Intermittent catheterization & 6 & \\
Suprapubic tapping & & \\
\hline
\end{tabular}

$72 \mathrm{~h}$ before testing (14 patients). Six patients were on alpha-adrenergic blockers. No patient had symptomatic urinary tract infection at the time of the study. Seven patients with bacteriura were treated with appropriate antibiotics.

\section{Protocol}

The water cystometries were done at a filling rate of $50 \mathrm{ml} / \mathrm{min}$ using a double lumen, transurethral $8 \mathrm{~F}$ Porges catheter. Perineal electromyography with concentric needle was also monitored during the cystometry. Rectal and urethral pressures were not systematically registered for this procedure. For all of the 20 patients, three consecutive cystometries were performed with a minimum interval of $10 \mathrm{~min}$ interposed between the fillings. (a) reproducibility: three consecutive cystometries (T1, T2 and T3) were performed without ES. The filling was stopped at the onset of an uninhibited bladder contraction of more than $15 \mathrm{~cm} \mathrm{H}_{2} \mathrm{O}$. (b) effects of ES: ES was applied to the dorsal penile nerve with Velcro ribbon electrodes (Dantec) or the dorsal clitoris nerve with a bipolar surface disc electrode (Dantec). A repetitive stimulation ( $5 \mathrm{~Hz})$ with rectangular stimuli (0.5 msec duration) was conducted with a Dantec Contrepoint EMG system. The stimulation strength was based upon the threshold intensity to obtain the bulbocavernosus reflex response on EMG. ${ }^{6}$ The 'threshold' was defined as the current at which a bulbocavernosus reflex appeared approximately $50 \%$ of the time, following the same stimulation parameters (that is, $5 \mathrm{~Hz}, 0.5 \mathrm{msec}$ pulse duration). This procedure was conducted prior to the first cystometry. The first cystometry was done without ES (baseline), followed by two others with ES of the pudendal nerve: one with a threshold current $(\mathrm{I}=$ threshold) and another with a current of twice the threshold ( $\mathrm{I}=2 \times$ threshold), at random. Continuous stimulation was applied during the filling phase of the cystometry, and stopped at the onset of an uninhibited bladder contraction of more than $15 \mathrm{~cm} \mathrm{H}_{2} \mathrm{O}$.
Discontinuous, non invasive cardiovascular monitoring was performed during the cystomanometries.

All subjects were fully informed about the experimental procedures and all gave their informed consent before any testing was performed. This study is part of a protocol approved by the local ethical committee.

Treatment and analysis of the data

Data were analysed with a Wilcoxon test using paired data. A significance level of 0.05 was adopted.

\section{Results}

Reproducibility of water cystometry

Table 2 presents the bladder capacity for the three consecutive cystometries. There is a tendency towards a

Table 2 Cystometric bladder capacity means and standard deviations for the reproducibility

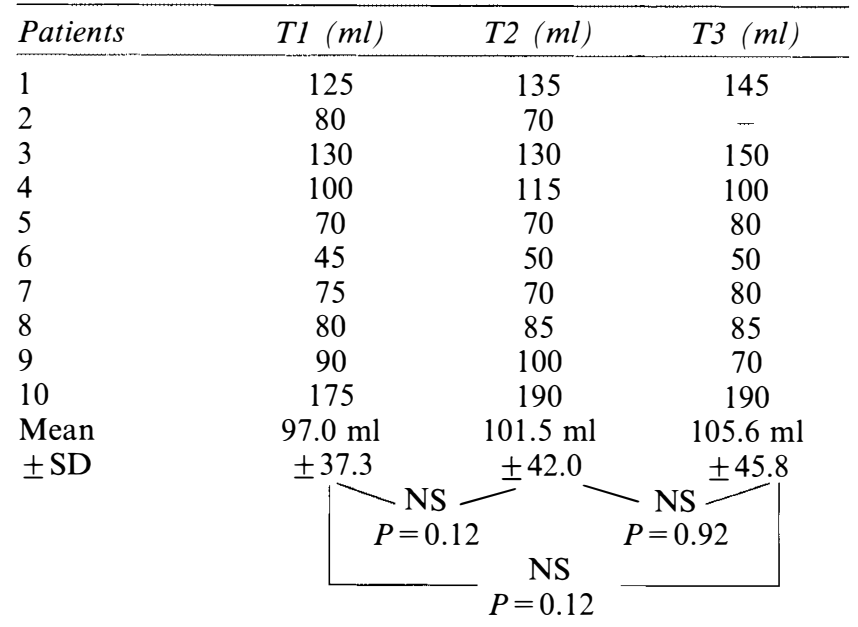


Table 3 Threshold current and cystometric bladder capacity means and standard deviations for the study of the ES. The asterisk indicates which one of the two cystometries with ES was first performed

\begin{tabular}{|c|c|c|c|c|}
\hline Patients & Threshold current ( $m A$ ) & Baseline ( $\mathrm{ml}$ ) & $I=$ threshold $(\mathrm{ml})$ & $I=2 \times$ threshold $(\mathrm{ml})$ \\
\hline 11 & 16 & 90 & 120 & $140^{*}$ \\
\hline 12 & 20 & 185 & 260 & $325^{*}$ \\
\hline 13 & 30 & 270 & $250^{*}$ & 240 \\
\hline 14 & 20 & 85 & 140 & $380 *$ \\
\hline 15 & 14 & 110 & $110^{*}$ & 230 \\
\hline 16 & 31 & 50 & 110 & $450 *$ \\
\hline 17 & 14 & 110 & $115^{*}$ & 290 \\
\hline 18 & 22 & 110 & $135^{*}$ & 180 \\
\hline 19 & 40 & 295 & 275 & $525^{*}$ \\
\hline 20 & 37 & 250 & 215 & $425^{*}$ \\
\hline \multirow{3}{*}{$\begin{array}{l}\text { Mean } \\
\pm S D\end{array}$} & $24.4 \mathrm{~mA}$ & $155.5 \mathrm{ml}$ & $173.0 \mathrm{ml}$ & $318.5 \mathrm{ml}$ \\
\hline & \pm 9.5 & \pm 87.5 & \pm 68.6 & \pm 125.1 \\
\hline & & & & 007 \\
\hline
\end{tabular}

higher mean bladder capacity with the repetition of fillings (respectively $97.0 \mathrm{ml}, 101.5 \mathrm{ml}, 105.6 \mathrm{ml}$ ), but no significant differences were found between $\mathrm{Tl}$, T2 and T3.

\section{Effect of ES}

Table 3 presents the results of the study. Threshold bulbocavernosus reflex responses were obtained with currents ranging from 14.0 to $40.0 \mathrm{~mA}$ (mean $24.4 \pm$ $9.5 \mathrm{~mA}$ ). The threshold stimulation produced a bladder capacity higher than the baseline values in six patients. However, no significant difference between the mean bladder capacities was found $(P=0.17)$. There was a significant increase in bladder capacity with ES at twice the threshold compared with the other two (baseline and threshold) cystometries (318.5 $\mathrm{ml} v s 155.5 \mathrm{ml}$ and $173.0 \mathrm{ml}$, respectively; $P<0.007$ ). A current strength of twice the threshold resulted in increased bladder capacity in all but one patient (patient no. 13). For this patient however, a further increase of the stimulation strength abolished the ongoing uninhibited bladder contraction. The current of twice the threshold evoked a clinical perineal contraction in all patients, threshold stimulation never did. Cessation of ES resulted in prompt bladder contraction in all patients. The effects of ES on the detrusor curves have been published elsewhere. ${ }^{8}$

The ES was well tolekated in all patients. Some patients with an incomplete spinal cord lesion described a tolerable discomfort. No changes in blood pressure or of pulse rate were noted during the performance of the studies.

\section{Discussion}

Reproducibility of bladder capacity during water cystometry in detrusor hyperreflexia had rarely been studied, though this technique is widely used to follow the short-term effects of various therapies such as injected or intravesical drugs, ${ }^{9}$ or perineal ES. ${ }^{5-7}$ The time between two successive cystometries and the rate of bladder filling are important factors with which to deal. When the second cystometry is performed a few minutes after the first one, there is a significant decrease of bladder capacity; ${ }^{10,11}$ with an interval of $20 \mathrm{~min}$ interposed between the fillings, no significant change in capacity is observed. ${ }^{11}$ In a population of SCI patients, Soler et al. found a good qualitative and quantitative reproducibility of cystometries performed from one day to another. ${ }^{12}$ The rate of bladder filling does not affect bladder capacity as long as the same rate is used for all cystometries. ${ }^{10,11}$ In our study of reproducibility, no significant difference was found with a repetition of three cystometries with a filling rate of $50 \mathrm{ml} / \mathrm{min}$, and a minimum rest interval of 10 min interposed between each filling.

In animal experiments, reflex sympathetic activation plays a major role in bladder relaxation either during physiological filling or in response to pudendal nerve stimulation. During bladder filling at physiological rate, the intravesical pressure initially rises slowly. This phenomenon is due primarily to the passive elastic and viscoelastic properties of the smooth muscle and connective tissue of the bladder wall. ${ }^{13}$ To adapt bladder tonus to volume increase during the last part of the filling phase, additional sympathetic reflexes are activated, resulting in active bladder inhibition. ${ }^{14}$ This effect is accomplished by a direct beta-adrenergic depression of the vesical smooth muscle, by excitation of the bladder base and urethra or by an alphaadrenergic modulation of cholinergic transmission in vesical parasympathetic ganglia. ${ }^{15,16}$

Bladder inhibition in response to intravaginal ES has been investigated in animal experiments: this inhibition is accomplished by two spinal reflex 
mechanisms, both of which have their afferent limbs in the pudendal nerves. The efferent limbs are the hypogastric and the pelvic nerves, respectively at low and high intravesical pressure. The response is frequency sensitive with an optimal transmission at about $5 \mathrm{~Hz}{ }^{17,18}$

Clinical studies in SCI patients have demonstrated the efficacy of perineal ES in short-term bladder inhibition. $^{5-7}$ ES of nonmuscular somatic afferent branches of the pudendal nerve (dorsal penile or clitoris nerves) could provide more specific bladder inhibition than other techniques available. ${ }^{6,7}$ Most effective parameters range from 5 to $10 \mathrm{~Hz}$ stimulation rates, with pulse durations from 0.2 to $1.0 \mathrm{msec}$. However, even though most authors advocate the use of strong ES, this was not demonstrated by Wheeler et $a l^{7}$ Our results conclusively prove that there is a doseresponse bladder inhibition with increasing current. Furthermore, the inhibition is well correlated with the presence of perineal contraction. These results are in agreement with those of Vereecken and Vodusek in SCI patients ${ }^{5,6}$ as well as with those in nonneurological patients presenting uninhibited overactive bladder, where maximal ES of the pudendal nerve represents an effective treatment. ${ }^{19}$

The mechanisms of action are not clearly known. If sympathetic reflexes are of importance in animals (cf. supra), their contribution to urine storage in man is still uncertain. ${ }^{16}$ In SCI patients however, the sympathetic outflow may play a more significant role as sympathetic over-activity occurs when spinal reflexes are activated, which may result in the syndrome of autonomic dysreflexia. ${ }^{20}$ Reflex activation of the sympathetic outflow to the lower urinary tract by bladder distension or by ES of pudendal nerve can lead to bladder neck dyssynergia ${ }^{21,22}$ or neck closure $^{23}$ which in turn could induce bladder inhibition.

The perineodetrusor (pudendal-to-pelvic) inhibitory reflex is another possible mechanism: ${ }^{6,7}$ the tone of the pelvic floor muscles provides an important tonic inhibitory influence on the bladder ${ }^{24,25}$ This cannot be the sole mechanism, as animal experiments demonstrated that bladder inhibition takes place, even though the urethral striated musculature was made paralytic with succinylcholine. ${ }^{17}$ Finally, neurotransmitters may also be involved: the sacral parasympathetic pathway to the urinary bladder is essentially a positive feedback circuit. In the absence of inhibitory modulation, this circuit triggers voiding at very low bladder volume, as is the case with detrusor hyperreflexia of SCI patients. The pudendal nerve afferents could stimulate the release of neurotransmitters involved in these putative inhibitory mechanisms such as the inhibitory amino acids (gaba aminobutyric acid and glycine) and enkephalins. ${ }^{16}$

In their classical work on the neurophysiological basis of bladder inhibition, Lindström et al. pointed out that the inhibition outlasted the stimulation by several minutes. ${ }^{18}$ This carry-over effect is also found in SCI patients, as post-stimulation cystometry showed an increase in bladder capacity compared with the baseline cystometry. ${ }^{6,7}$ This post-stimulation inhibitory effect represents the background for the therapeutic use of perineal ES. Former studies stated that maximal ES applied via an anal plug (pulse duration $1 \mathrm{msec}$, rate $20 \mathrm{~Hz}$ ) with current up to $150 \mathrm{~mA}$ resulted in an improvement of detrusor hyperreflexia in SCI patients. $^{2-4}$ However interesting these results are, they were never confirmed. Chronic (home) use of ES is an alternative to maximal ES, advocated by Wheeler et al. The stimulation strength is calculated with regard to perineal contraction with current up to $40 \mathrm{~mA}$ (pulse width $0.25 \mathrm{msec}$, rate $5 \mathrm{~Hz}$ ). ${ }^{26}$

In summary, we confirmed the efficacy of pudendal nerve ES in inhibiting detrusor hyperreflexia in SCI patients. We also stressed the importance of current strength, as this inhibition was only achieved with the highest current strength (twice the bulbocavernosus reflex threshold). If so, one can reasonably assume that the reported carry-over effect is also dependent on the intensity of the current strength. Studies are needed to determine if maximal pudendal ES could represent an alternative treatment of detrusor hyperreflexia in SCI patients. Such studies are in progress.

\section{Acknowledgements}

This work was supported by a grant from INSERM (921106). The authors wish to thank Professor I Perkash, Stanford University, for peer review of the manuscript.

\section{References}

1 Godec C, Cass AS, Ayala GF. Bladder inhibition with functional electrical stimulation. Urology 1975; 6: 663-666.

2 Godec C, Cass AS. Electrical stimulation for voiding dysfunction after spinal cord injury. $J$ Urol 1979; 121: 73-75.

3 Janez J, Plevnik S, Suhel P. Urethral and bladder responses to anal electrical stimulation. J Urol 1979; 122: 192 - 194.

4 Merrill DC. The treatment of detrusor incontinence by electrical stimulation. J Urol 1979; 122: 515-517.

5 Vereecken RL, Das J, Grisar P. Electrical sphincter stimulation in the treatment of detrusor hyperreflexia of paraplegics. Neurourol Urodyn 1984; 3: $145-154$.

6 Vodusek DB, Light JK, Libby JM. Detrusor inhibition induced by stimulation of pudendal nerve afferents. Neurourol Urodyn 1986; 5: $381-389$

7 Wheeler JS, Walter JS, Zaszczurynski PJ. Bladder inhibition by penile nerve stimulation in spinal cord injury patients. $J$ Urol 1992; 147: $100-103$.

8 Prévinaire JG, Soler JM, Boileau G, Chelihi D, Delahaye H, Schumacker $\mathrm{P}$, Vanvelcenaher J, Vanhée JL, Perrigot M. Effet à court terme de l'électrostimulation cutanée du nerf pudendal sur l'hyperactivité vésicale chez le blessé médullaire. Ann Réadaptation Méd Phys 1995; 38: $211-216$.

9 Susset JG. Cystometry. In: Krane RJ, Siroky MB (eds). Clinical Neurourology. 2nd edn. Little, Brown: Boston 1991, pp 163-184.

10 Grynderup V. Double cystometry in the uninhibited neurogenic bladder. Acta Neurol Scand 1966; 42: 67-77.

11 Jensen D. Pharmacological studies of the uninhibited neurogenic bladder. Acta Neurol Scand 1981; 64: 145-174. 
12 Soler JM, Andoque F, Bouffard-Vercelli M, Perrigot M. Reproductibilité des cystomanométries et sphinctérométries à eau des blessés vertébro-médullaires. A propos de 30 cas. Sifud Cannes, 1989; 2: 146 - 149.

13 Tang PC, Ruch TC. Non-neurogenic basis of bladder tone. Am J Phyiol 1955; 181: 249-257.

14 Edvardsen P. Nervous control of urinary bladder in cat. I. The collecting phase. Acta Physiol Scand 1968; 72:157-171.

15 de Groat WC, Lalley PM. Reflex firing in the lumbar sympathetic outflow to activation of vesical afferent fibres. J Physiol 1972; 226: $289-309$.

16 de Groat WC, Booth AM, Yoshimura N. Neurophysiology of micturition and its modification in animal models of human disease. In: Maggi CA (ed). The autonomic nervous system: Nervous control of the urogenital system, vol 3. Harwood Academic Publishers: London 1993, pp 227-290.

17 Fall M, Erlandson BE, Carlsson CA, Lindström S. The effect of intravaginal electrical stimulation on the feline urethra and urinary bladder. Neuronal mechanisms. Scand J Urol Nephrol 1978; Suppl 44: $19-30$.

18 Lindström S, Fall M, Carlsson CA, Erlandson BE. The neurophysiological basis of bladder inhibition in response to intravaginal electrical stimulation. J Urol 1983; 129: 405-410.
19 Ohlsson BL, Fall M, Frankenberg-Sommar S. Effects of external and direct pudendal nerve maximal electrical stimulation in the treatment of the uninhibited overactive bladder. Br J Urol 1989; 64: $374-380$.

20 Mathias CJ, Frankel HL. Clinical manifestations of malfunctioning sympathetic mechanisms in tetraplegia. J Auton Nerv Syst 1983; 7: $303-312$.

21 Prévinaire JG, Soler JM, Hanson P. Skin potential recordings during cystometry in spinal cord injured patients. Paraplegia 1993; 31: $13-21$.

22 Schurch B, Yasuda K, Rossier AB. Detrusor bladder neck dyssynergia revisited. J Urol 1994; 152: 2066-2070.

23 Bors E. Segmental and peripheral innervation of the urinary bladder. J Nerv Ment Dis 1952; 116: $572-578$.

24 Denny-Brown D, Robertson EG. On the physiology of micturition. Brain 1933; 56: 149-190.

25 Teague CT, Merrill DC. Electric pelvic floor stimulation. Mechanism of action. Invest Urol 1977; 15: 65-69.

26 Wheeler JS, Walter JS, Sibley P. Management of incontinent SCI patients with penile stimulation: preliminary results. $\mathrm{J} \mathrm{Am}$ Paraplegia Soc 1994; 17: 55-59. 